\title{
Effect of Reduced Reflective Wave Propagation on Overhead Contact Lines in Overlap Section
}

\author{
Takamasa HAYASAKA \\ Researcher, Contact Line Structures, Power Supply Technology Div.
}

\begin{abstract}
The vibration of overhead contact line caused by a patograph passing through an overlap section propagates on the overhead contact line and reflects at an anchor mast. The reflection wave thus generated returns to the pantograph and worsens the performance of current collection. To reduce the reflection wave with a damper, we used a model to calculate the constant and installation point for the damper, which were examined with a pantograph/catenary simulation program to prove that the installation of a damper decreased the contact loss ration and contact force fluctuations. This paper introduces the simulation that uses the results of theoretical calculation to reduce the reflection wave using a damper, evaluates the effectiveness of the damper from the viewpoint of contact loss ratio and contact force fluctuations.
\end{abstract}

Keywords: reflection wave, overlap section, damper, simulation,

\section{Introduction}

Current collection using pantographs and overhead contact lines is commonly used to supply power to electric trains. In the simple catenary structure, for example, the messenger wire is supported at approximately equal intervals and carries the contact wire using hangers arranged at 5-meter intervals. Given the catenary structure, however, the hangers and support points become the source of rigidity fluctuation in the overhead contact lines at interval determined by the span length and hanger spacings ${ }^{1) 2}$. If a pantograph collects current from an overhead contact line with rigidity fluctuations, the waves thus generated are propagated in the overhead contact line, reflected at the hard points, and are returned to the pantograph, degrading current collection performance. A typical hard point on the overhead contact line is the edge of overlap sections that are set at the anchor mast, where waves will be reflected with a small decay coefficient.

If a pantograph approaches an overlap section, it will be affected by the wave reflected from the anchor mast. Furthermore, intense vibration of the overhead contact line is caused from the pantograph that gives shock to the contact wire when it shifts from one contact wire to another at the overlap section, and the residual vibration affects the current collection performance of the following pantographs. Although Aboshi and Nakai devised spring and damper hangers to reduce the vibration of overhead contact wires, they did not take the reflection wave into consideration ${ }^{3)}$

For the purposes of this study, the effect of the damper constant and damper installation points were calculated and analyzed in an effort to reduce the wave reflected at the anchor mast in overlap sections. If damping thus calculated were adopted, we would be able to improve current collection performance by eliminating the reflection wave, though one damper is effective only for one frequency. These effects were examined using with catenary-pantograph simulation program to prove that the performance of current collection was improved when dampers were installed on contact wires ${ }^{4) 5}$.

In this report, we examine the results of damper installation on both contact wires and messenger wires, obtaining the optimal damper constant and damper installation points in order to improve current collection performance from the viewpoint of the contact loss ratio and contact force fluctuations at overlap sections.

\section{Current collection performance in overlap sections}

There are a number of hard points on overhead contact lines, such as hangers, support points and anchor masts. Among these points, the anchor mast is the most typical hard point.

Figure 1 represents two pantographs passing through an overlap section. The first pantograph shifts from the overhead contact line A to B and, as it strikes the latter, it generates a wave that is propagated and reflected at the anchor mast. The wave reflected at the anchor mast must be reduced, since it affects the current collection capability of the first pantograph and generates a source of vibration, the residual vibration influencing the current collection by the next pantograph that follows.

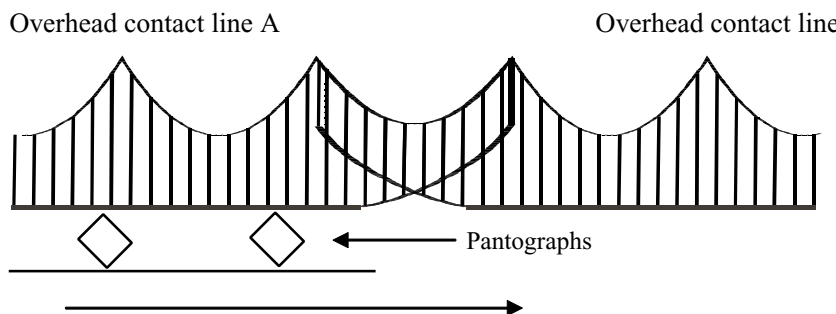

Fig. 1 Pantographs passing through an overlap section

\section{Modeling of overhead contact line with a damper}

Figure 2 shows a case where the damper edge has been set at the contact wire and the fixed point near the anchor mast in the overlap section, and Fig. 3 a case where 


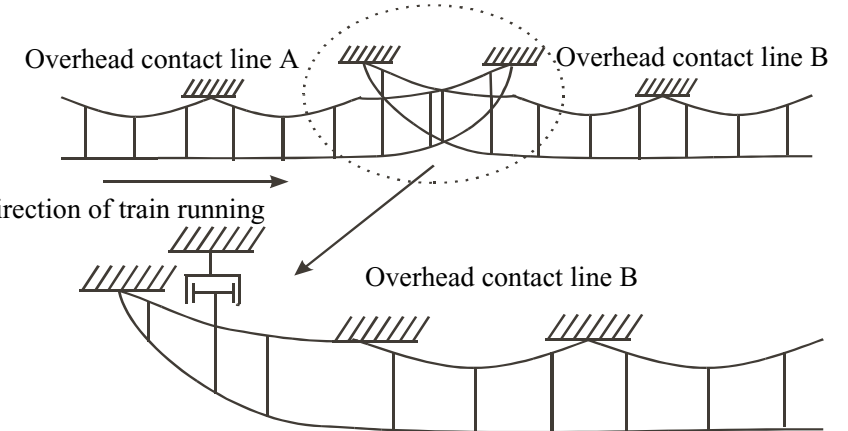

Fig. 2 Damper installation of overlap section

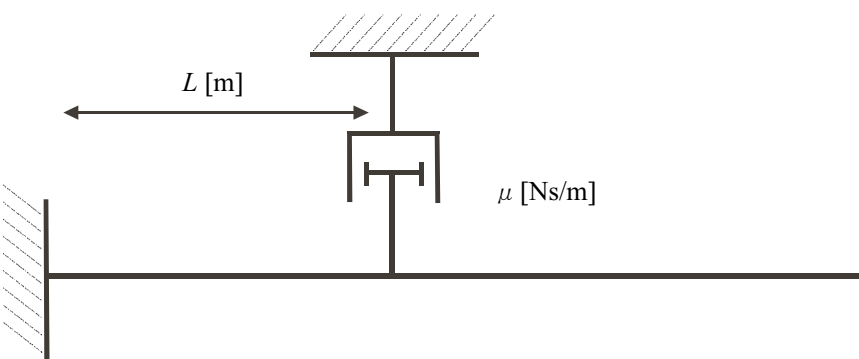

Fig. 3 Mechanical model of damper-line system

the messenger wire and the contact wire in Fig. 2 are regarded as a chord with a damper having the damper constant of $\mu(\mathrm{Ns} / \mathrm{m})$ set at a distance $L(\mathrm{~m})$ from the anchor mast. In Fig. 3, the tensile strength and the line density are calculated by the following equations, where $T_{M}(\mathrm{~N})$ and $T_{T}(\mathrm{~N})$ are, respectively, the tensile strength of contact wire and messenger wire and $\rho_{M}(\mathrm{~kg} / \mathrm{m})$ and $\rho_{T}$ $(\mathrm{kg} / \mathrm{m})$ are, respectively, the line density of contact wire and messenger wire.

$$
\begin{aligned}
& T=T_{M}+T_{T} \\
& \rho=\rho_{M}+\rho_{T}
\end{aligned}
$$

Although the above case concerns a damper installed on the contact wire, the same also holds true when the damper is installed to the messenger wires.

\section{Reflection wave reduction requirements}

Figure 4 shows the incidence wave, the penetration wave, and its reflection wave, the reflection wave, the point of origin, and an anchor mast, where the point of origin and the anchor mast are expressed as $x=0$ and $x=L$, respectively. These waves are defined by equations (1) to (4) as follows.

$$
\begin{aligned}
& \text { Incidence wave }: A_{1} \exp \{i \omega(t-x / c)\} \\
& \text { Penetration wave }: A_{2} \exp \{i \omega(t-x / c)\}
\end{aligned}
$$

Penetration wave's reflection wave : $A_{3} \operatorname{Exp}\{i \omega(t+x / c)\}$

Reflection wave : $A_{4} \operatorname{Exp}\{i \omega(t+x / c)\}$

where $A_{1}$ to $A_{4}$ represent the amplitude of each wave, and $t, \omega$ and $c$ are the time, angular frequency, and wave velocity respectively.

We calculated what was needed to make the reflection wave zero in Fig. 4.

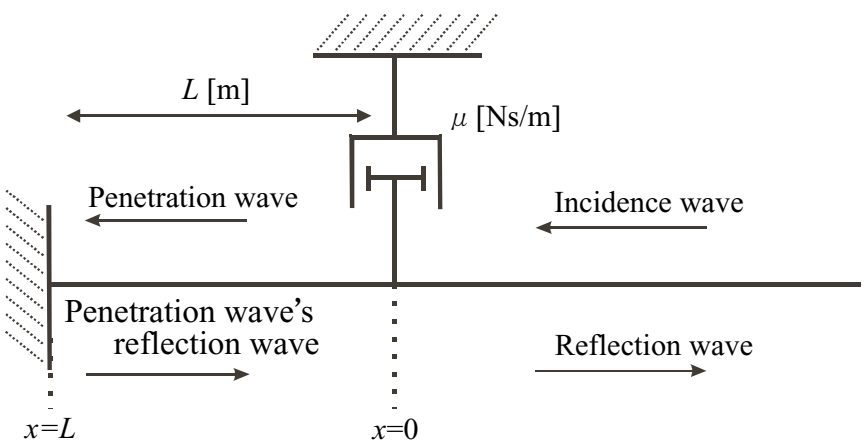

Fig. 4 Definition of each propagating wave in the overlap section

On the right-, and left-hand sides of the damper, the following were calculated.

$$
\begin{aligned}
& y_{1}=A_{1} \exp \{i \omega(t-x / c)\}+A_{4} \exp \{i \omega(t+x / c)\} \\
& y_{2}=A_{2} \exp \{i \omega(t-x / c)\}+A_{3} \exp \{i \omega(t+x / c)\}
\end{aligned}
$$

At $x=0$, equation ( 7 ) holds.

$A_{1}+A_{4}=A_{2}+A_{3}$

The following equation is led to at $x=L$, since it is a fixed point.

$$
A_{3}=-A_{2} \exp (-2 i \omega L / c)
$$

When the damper constant is denoted by $\mu$, the following equation is derived using the principle of dynamic equilibrium,

$$
\left.\mu \frac{\partial y_{1}}{\partial t}\right|_{x=0}=-\left.T \frac{\partial y_{1}}{\partial x}\right|_{x=0}+\left.T \frac{\partial y_{2}}{\partial x}\right|_{x=0}
$$

After some manipulation to make the reflection wave zero, the resulting equation (10) is denoted thus:

$$
\exp (2 i \omega L / c)=(\mu c-2 T) / \mu c
$$

For this purpose, it should be noted that the following conditions must be satisfied.

$$
\mu=\sqrt{T \rho} \quad L=\frac{1}{4 f} \sqrt{\frac{T}{\rho}}
$$

Figure 5 shows the relationship between the amplitude of reflection wave with the damper constant, and Fig. 6

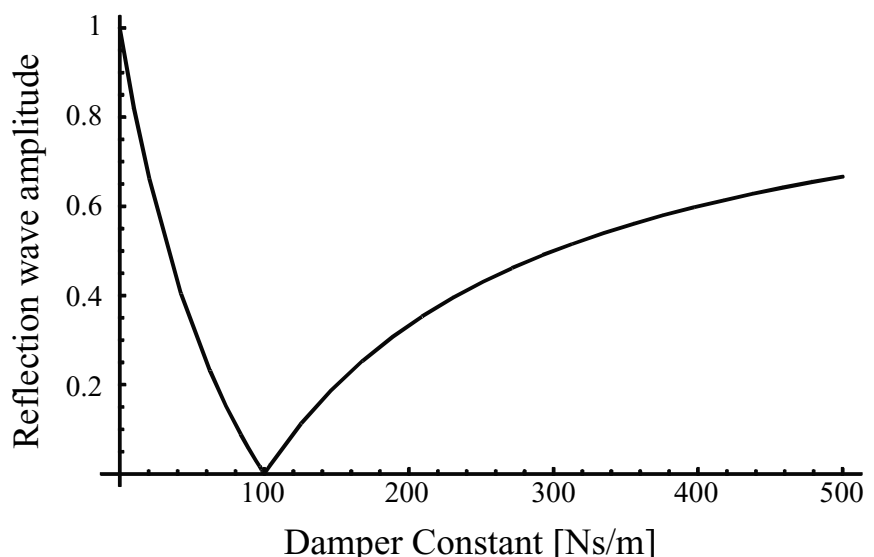

Fig. 5 Reflection wave amplitude on damper constant (frequency constant $1[\mathrm{~Hz}]$ ) 


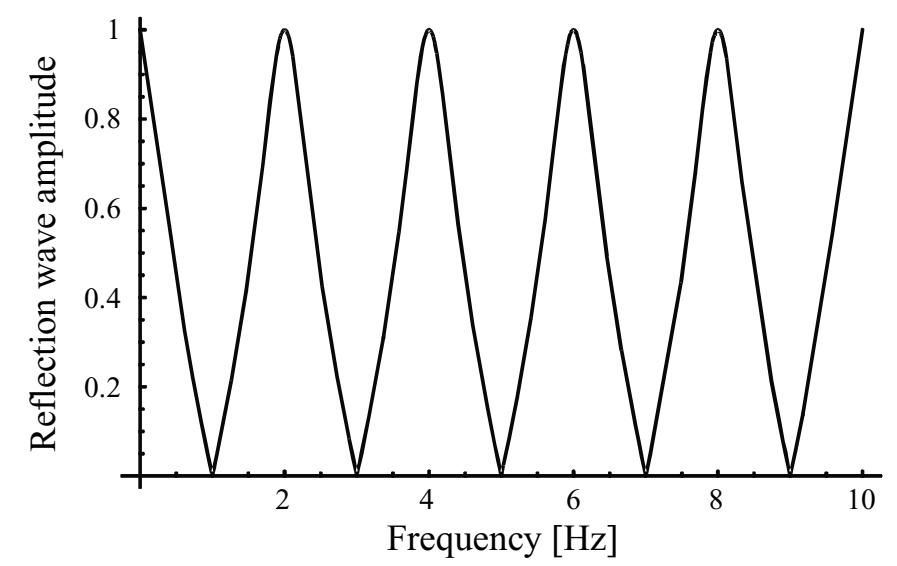

Fig. 6 Reflection wave amplitude on frequency (damper constant $100[\mathrm{Ns} / \mathrm{m}])$

that with the damper installation point, when a sine wave is input and the tensile strength, density of overhead contact line and its length are set at $10,000 \mathrm{~N}, 1 \mathrm{~kg} / \mathrm{m}$ and $150 \mathrm{~m}$, respectively. It proves that the damper constant and the damper installation point affect the amplitude of the reflection wave. Therefore, close attention must be paid to the frequency of the overhead contact line when determining the damper installation point.

\section{Verification by the distributed mass system}

Equation (11) is effective when steady incident waves enter the damper, but it does not reflect the shock wave in overhead contact lines caused by the pantographs. To address this problem, we represented the overhead contact line in Fig. 3 using a distributed mass system, considered equations (12) and (13) for typical coupled vibration, and examined the movement of the overhead contact line by simulation. The anchor mast and the entry edge incident wave acted as a fixing point and free edge, respectively. We used simulation to examine problems that arise with one cycle waves as well as steady waves. To simplify the calculation, tensile strength, density and the length of the overhead contact line were set at 10,000 N, $1 \mathrm{~kg} / \mathrm{m}$ and $150 \mathrm{~m}$, respectively. Settings for incident wave frequency, - damper, and the distance between the anchor mast and damper were $1 \mathrm{~Hz}, 100 \mathrm{Ns} / \mathrm{m}$ and $25 \mathrm{~m}$, respectively. The symbols $m_{i}$ and $x_{i}$ in equations (12) and (13) represent the mass and displacement in the distributed mass system.

$$
\begin{aligned}
& m_{i} \frac{d^{2} x_{i}}{d t^{2}}=-T\left(x_{i}-x_{i-1}\right) \ldots \ldots \ldots \ldots \ldots \ldots \ldots \ldots \ldots \ldots \\
& m_{i} \frac{d^{2} x_{i}}{d t^{2}}=-T\left(2 x_{i}-x_{i-1}-x_{i+1}\right)-\sqrt{T \rho} \frac{d x_{i}}{d t}
\end{aligned}
$$

\section{Verification by a catenary - pantograph simulation program}

We verified the validity of equation (11) by using a catenary-pantograph simulation program for the heavy, simple catenary used in DC sections in Japan as a bench-

\begin{tabular}{|c|c|}
\hline $\begin{array}{c}\text { Tensile strength and type of mes- } \\
\text { senger wire }\end{array}$ & St135, $1.09[\mathrm{~kg} / \mathrm{m}], 19.6[\mathrm{kN}]$ \\
\hline $\begin{array}{l}\text { Tensile strength and type of con- } \\
\text { tact wire }\end{array}$ & $\mathrm{GT} 170,1.51[\mathrm{~kg} / \mathrm{m}], 14.7[\mathrm{kN}]$ \\
\hline Span length and number & $50[\mathrm{~m}] 7$ spans \\
\hline Hanger interval & $5[\mathrm{~m}]$ \\
\hline Number and model of pantographs & 5 pantographs WPS27C \\
\hline Static upward force of pantograph & $59[\mathrm{~N}]$ \\
\hline Condition of damper & $\begin{array}{c}\text { Bilaterally effective single-side } \\
\text { effective }\end{array}$ \\
\hline Damper constant & 150300450600 [Ns/m] \\
\hline $60[\mathrm{~m}]$ & $40[\mathrm{~m}] \quad 40[\mathrm{~m}]$ \\
\hline
\end{tabular}

Table 1 Simulation specifications

Fig. 7 Pantograph arrangement

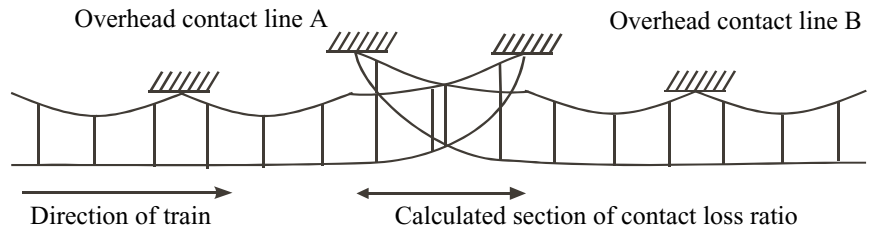

Fig. 8 Sections to calculate the contact loss ratio and maximum contact force

\begin{tabular}{|c|c|c|}
\hline Number & Damper constant & Damper installation point \\
\hline $\mathrm{A}(\mathrm{B})-0$ & 0 & Nothing \\
\hline $\mathrm{T}(\mathrm{M}) \mathrm{S}(\mathrm{D}) \mathrm{A}(\mathrm{B})-1$ & $150[\mathrm{Ns} / \mathrm{m}]$ & $26[\mathrm{~m}] \quad(1.1 \mathrm{~Hz})$ \\
\hline $\mathrm{T}(\mathrm{M}) \mathrm{S}(\mathrm{D}) \mathrm{A}(\mathrm{B})-2$ & $150[\mathrm{Ns} / \mathrm{m}]$ & $29[\mathrm{~m}] \quad(1.0 \mathrm{~Hz})$ \\
\hline $\mathrm{T}(\mathrm{M}) \mathrm{S}(\mathrm{D}) \mathrm{A}(\mathrm{B})-3$ & $150[\mathrm{Ns} / \mathrm{m}]$ & $32[\mathrm{~m}] \quad(0.9 \mathrm{~Hz})$ \\
\hline $\mathrm{T}(\mathrm{M}) \mathrm{S}(\mathrm{D}) \mathrm{A}(\mathrm{B})-4$ & $150[\mathrm{Ns} / \mathrm{m}]$ & $36[\mathrm{~m}] \quad(0.8 \mathrm{~Hz})$ \\
\hline $\mathrm{T}(\mathrm{M}) \mathrm{S}(\mathrm{D}) \mathrm{A}(\mathrm{B})-5$ & $150[\mathrm{Ns} / \mathrm{m}]$ & $41[\mathrm{~m}] \quad(0.7 \mathrm{~Hz})$ \\
\hline $\mathrm{T}(\mathrm{M}) \mathrm{S}(\mathrm{D}) \mathrm{A}(\mathrm{B})-6$ & $300[\mathrm{Ns} / \mathrm{m}]$ & $26[\mathrm{~m}] \quad(1.1 \mathrm{~Hz})$ \\
\hline $\mathrm{T}(\mathrm{M}) \mathrm{S}(\mathrm{D}) \mathrm{A}(\mathrm{B})-7$ & $300[\mathrm{Ns} / \mathrm{m}]$ & $29[\mathrm{~m}] \quad(1.0 \mathrm{~Hz})$ \\
\hline $\mathrm{T}(\mathrm{M}) \mathrm{S}(\mathrm{D}) \mathrm{A}(\mathrm{B})-8$ & $300[\mathrm{Ns} / \mathrm{m}]$ & $32[\mathrm{~m}] \quad(0.9 \mathrm{~Hz})$ \\
\hline $\mathrm{T}(\mathrm{M}) \mathrm{S}(\mathrm{D}) \mathrm{A}(\mathrm{B})-9$ & $300[\mathrm{Ns} / \mathrm{m}]$ & $36[\mathrm{~m}] \quad(0.8 \mathrm{~Hz})$ \\
\hline $\mathrm{T}(\mathrm{M}) \mathrm{S}(\mathrm{D}) \mathrm{A}(\mathrm{B})-10$ & $300[\mathrm{Ns} / \mathrm{m}]$ & $41[\mathrm{~m}] \quad(0.7 \mathrm{~Hz})$ \\
\hline $\mathrm{T}(\mathrm{M}) \mathrm{S}(\mathrm{D}) \mathrm{A}(\mathrm{B})-11$ & $450[\mathrm{Ns} / \mathrm{m}]$ & $26[\mathrm{~m}] \quad(1.1 \mathrm{~Hz})$ \\
\hline $\mathrm{T}(\mathrm{M}) \mathrm{S}(\mathrm{D}) \mathrm{A}(\mathrm{B})-12$ & $450[\mathrm{Ns} / \mathrm{m}]$ & $29[\mathrm{~m}] \quad(1.0 \mathrm{~Hz})$ \\
\hline $\mathrm{T}(\mathrm{M}) \mathrm{S}(\mathrm{D}) \mathrm{A}(\mathrm{B})-13$ & $450[\mathrm{Ns} / \mathrm{m}]$ & $32[\mathrm{~m}] \quad(0.9 \mathrm{~Hz})$ \\
\hline $\mathrm{T}(\mathrm{M}) \mathrm{S}(\mathrm{D}) \mathrm{A}(\mathrm{B})-14$ & $450[\mathrm{Ns} / \mathrm{m}]$ & $36[\mathrm{~m}] \quad(0.8 \mathrm{~Hz})$ \\
\hline $\mathrm{T}(\mathrm{M}) \mathrm{S}(\mathrm{D}) \mathrm{A}(\mathrm{B})-15$ & $450[\mathrm{Ns} / \mathrm{m}]$ & $41[\mathrm{~m}] \quad(0.7 \mathrm{~Hz})$ \\
\hline $\mathrm{T}(\mathrm{M}) \mathrm{S}(\mathrm{D}) \mathrm{A}(\mathrm{B})-16$ & $600[\mathrm{Ns} / \mathrm{m}]$ & $26[\mathrm{~m}] \quad(1.1 \mathrm{~Hz})$ \\
\hline $\mathrm{T}(\mathrm{M}) \mathrm{S}(\mathrm{D}) \mathrm{A}(\mathrm{B})-17$ & $600[\mathrm{Ns} / \mathrm{m}]$ & $29[\mathrm{~m}] \quad(1.0 \mathrm{~Hz})$ \\
\hline $\mathrm{T}(\mathrm{M}) \mathrm{S}(\mathrm{D}) \mathrm{A}(\mathrm{B})-18$ & $600[\mathrm{Ns} / \mathrm{m}]$ & $32[\mathrm{~m}] \quad(0.9 \mathrm{~Hz})$ \\
\hline $\mathrm{T}(\mathrm{M}) \mathrm{S}(\mathrm{D}) \mathrm{A}(\mathrm{B})-19$ & $600[\mathrm{Ns} / \mathrm{m}]$ & $36[\mathrm{~m}] \quad(0.8 \mathrm{~Hz})$ \\
\hline $\mathrm{T}(\mathrm{M}) \mathrm{S}(\mathrm{D}) \mathrm{A}(\mathrm{B})-20$ & $600[\mathrm{Ns} / \mathrm{m}]$ & $41[\mathrm{~m}] \quad(0.7 \mathrm{~Hz})$ \\
\hline
\end{tabular}

Table 2 Simulation parameters

mark as shown in Table 1 - (see Fig. 7 for the pantograph arrangement). The train speed in the simulation was $120 \mathrm{~km} / \mathrm{h}$. In Fig. 7, running test A denotes that carried out forwards 
with the train pantographs at $40 \mathrm{~m}$ - intervals, running test $\mathrm{B}$ that conducted in reverse with the pantographs at $60 \mathrm{~m}$ - intervals. The damper constant was set at 150 , 300,450 and $600 \mathrm{Ns} / \mathrm{m}$ for both the bilaterally and singleside effective dampers. Dampers were set at points 26, $29,32,36$ and $41 \mathrm{~m}$ distant from the anchor on the line B side where larger pantograph contact force fluctuations were anticipated corresponding to contact wire vibration frequencies of $1.1,1.0,0.9,0.8$ and $0.7 \mathrm{~Hz}$, respectively. Figure 8 shows the sections for which simulated contact loss ratio and maximum contact force were calculated.

Table 2 shows the simulation parameters, in which symbols $\mathrm{A}$ and $\mathrm{B}$ represent the respective running tests and $\mathrm{T}$ and $\mathrm{M}$ the cases where the damper was installed on the contact wire and the messenger wire, respectively. $\mathrm{S}$ corresponds to single-side effective damping and $\mathrm{D}$ to those of bilaterally effective damping.

\section{Results of simulation}

\subsection{Results of verification of the distributed mass system}

Figure 9 presents the verification results of the distributed mass system, where the conditions were set to comply with equation (11). We input incident waves to simulate the reflection wave for one cycle of the sine wave into this system from the right side in Fig. 9. The amplitude of sine wave reflected at the anchor mast differed when bilaterally or single-side effective dampers were used. Taking the incident wave amplitude as unity, that of the reflection wave was 0.35 with bilaterally dampers and 0.93 with single-side dampers. When a steady incidence wave entered the damper, the penetration wave and its reflection wave are synthesized between the anchor mast and the damper to generate a stationary wave of $1 / 4$ wavelength.

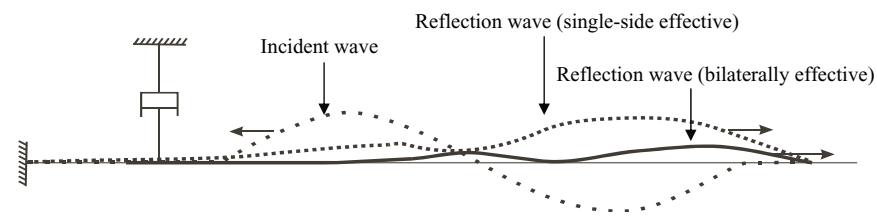

Fig. 9 Results of distributed system verification

\subsection{Verified results of catenary-pantograph simulation program}

Table 3 shows the representative results of contact loss ratio calculated by the simulation program, which proves that the bilaterally effective damping of 300 or $450 \mathrm{Ns} / \mathrm{m}$ is more effective when installed at the contact wire or messenger wire.

Figures 10 and 11 show the contact force fluctuation of fifth pantograph. These Figs. indicate that the contact force fluctuations near span No. 8 is reduced by the damper installed at the overlap section. Figures 12 and 13 also show that the standard deviation of contact force decreases when a damper is installed.

Figure 14 represents the differences between the minimum and maximum contact wire strain values when a bi-
Table 3 Simulation results (contact loss ratio)

\begin{tabular}{|c|c|c|c|c|c|}
\hline \multirow[b]{2}{*}{ Number } & \multicolumn{5}{|c|}{ No. of pantograph } \\
\hline & $\begin{array}{l}\text { First } \\
(\%)\end{array}$ & $\begin{array}{c}\text { Second } \\
(\%)\end{array}$ & $\begin{array}{c}\text { Third } \\
(\%)\end{array}$ & $\begin{array}{c}\text { Fourth } \\
(\%)\end{array}$ & $\begin{array}{c}\text { Fifth } \\
(\%)\end{array}$ \\
\hline A - 0 & 6 & 0 & 0 & 9 & 18 \\
\hline B -0 & 6 & 12 & 19 & 0 & 0 \\
\hline TSA - 9 & 0 & 0 & 0 & 0 & 1 \\
\hline TDA - 9 & 0 & 0 & 0 & 0 & 0 \\
\hline TDA - 14 & 0 & 0 & 0 & 0 & 0 \\
\hline TDA - 15 & 0 & 0 & 0 & 0 & 0 \\
\hline MDA - 6 & 0 & 0 & 0 & 0 & 0 \\
\hline MDA - 7 & 0 & 0 & 0 & 0 & 1 \\
\hline MDA - 8 & 0 & 0 & 0 & 0 & 0 \\
\hline MDA - 9 & 0 & 0 & 0 & 0 & 0 \\
\hline MDA - 10 & 0 & 0 & 0 & 0 & 0 \\
\hline MDA - 11 & 0 & 0 & 0 & 0 & 0 \\
\hline MDA - 13 & 0 & 0 & 0 & 0 & 0 \\
\hline MDA - 14 & 0 & 0 & 0 & 0 & 0 \\
\hline MDA - 15 & 0 & 0 & 0 & 0 & 0 \\
\hline TSB - 9 & 0 & 1 & 1 & 2 & 0 \\
\hline TDB - 9 & 0 & 0 & 1 & 3 & 0 \\
\hline TDB - 14 & 0 & 0 & 0 & 3 & 0 \\
\hline TDB - 15 & 0 & 0 & 0 & 3 & 0 \\
\hline MDB - 6 & 0 & 0 & 0 & 3 & 0 \\
\hline MDB - 7 & 0 & 0 & 1 & 3 & 0 \\
\hline MDB - 8 & 0 & 0 & 0 & 3 & 0 \\
\hline MDB - 9 & 0 & 0 & 1 & 3 & 0 \\
\hline MDB - 10 & 0 & 0 & 0 & 3 & 0 \\
\hline MDB - 11 & 0 & 0 & 1 & 3 & 0 \\
\hline MDB - 13 & 0 & 0 & 0 & 3 & 0 \\
\hline MDB - 14 & 0 & 0 & 0 & 3 & 0 \\
\hline MDB - 15 & 0 & 0 & 0 & 3 & 0 \\
\hline
\end{tabular}

laterally effective or single-side effective damper is installed and pantographs pass through the overlap section. In these results, the strain with the bilaterally effective damper is larger than that of the single-side effective by about $20 \%$.

It is more effective to install a damper at the 36 or $41 \mathrm{~m}$ point $(0.8$ or $0.7 \mathrm{~Hz})$ along a contact wire or messenger wire. The result does not agree with the value obtained by substituting the simulation parameter in equation (11), but this problem will be solved if we allow for the Doppler effect. The installation point using equation (11) is modified by the following equation.

$$
L=\frac{1}{4 f} \sqrt{\frac{T}{\rho}} \Rightarrow \frac{S(C+v)}{2 \alpha C}
$$

\section{Conclusion}

This report has presented measures to improve current collection using a damper to reduce the reflection wave from anchor masts at overlap sections and modeled a damper and an overlap section. We calculated data to 


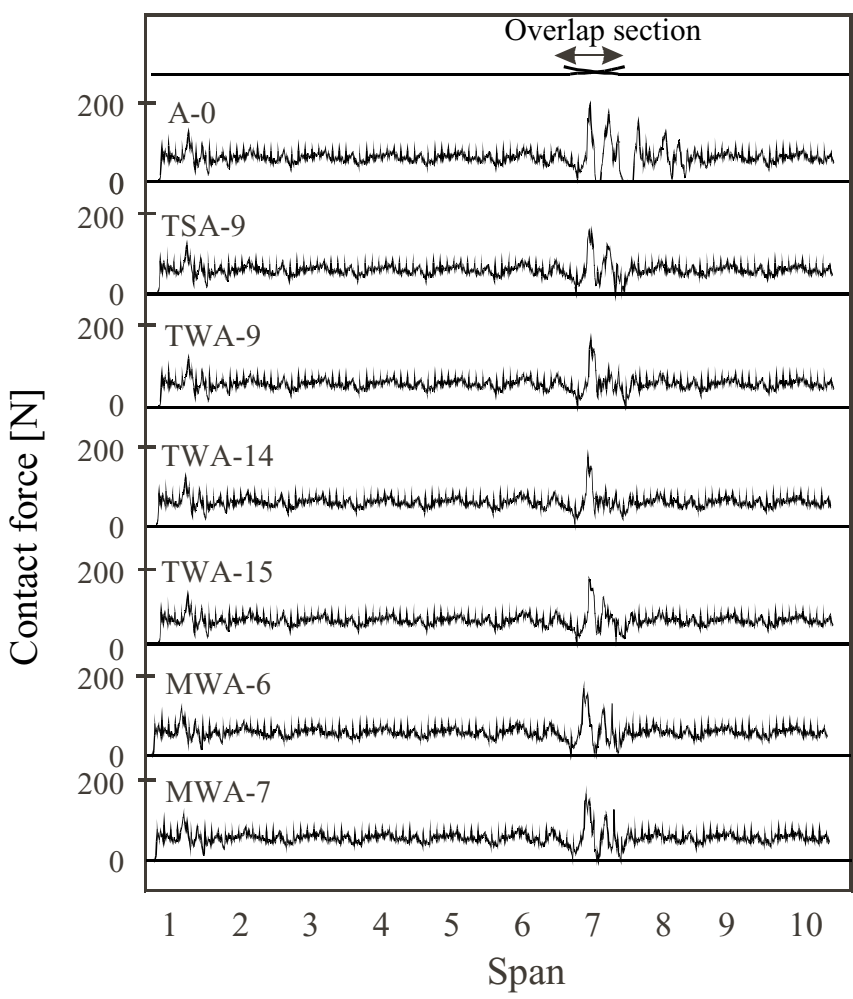

Fig. 10 Contact force fluctuation of the fifth pantograph (A-0 to MDA-7)

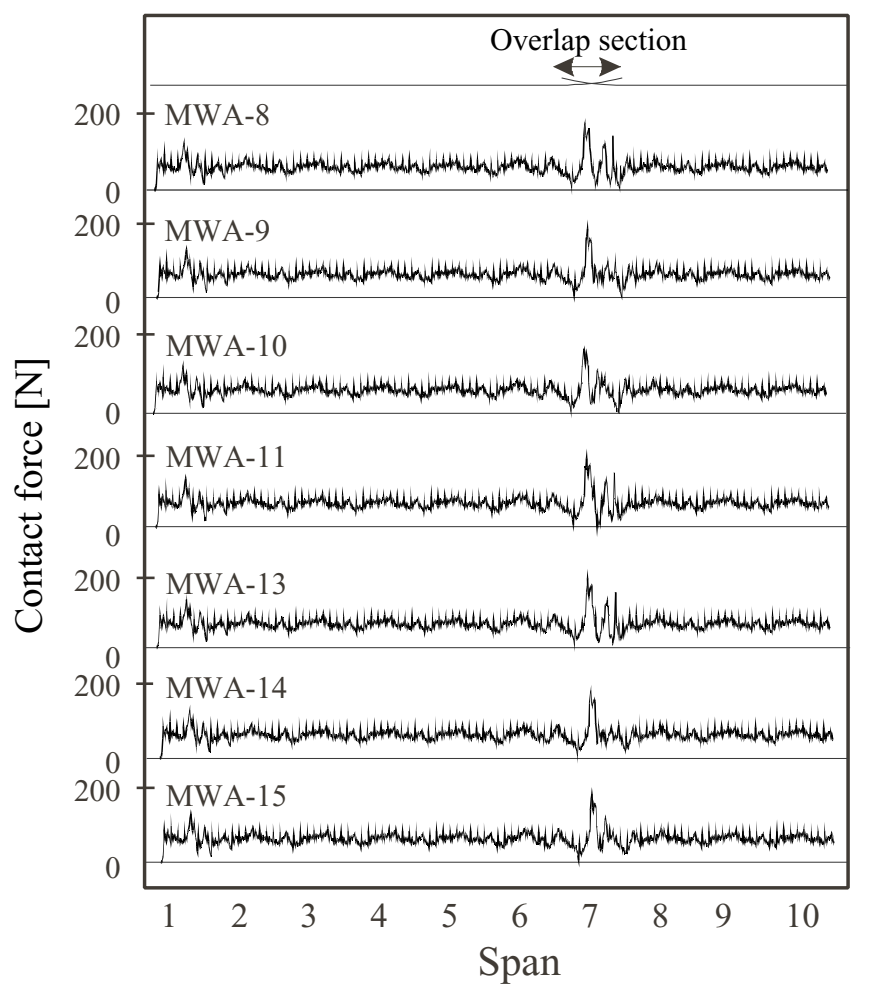

Fig. 11 Contact force fluctuation of the fifth pantograph (MDA-8 to MDA-15)

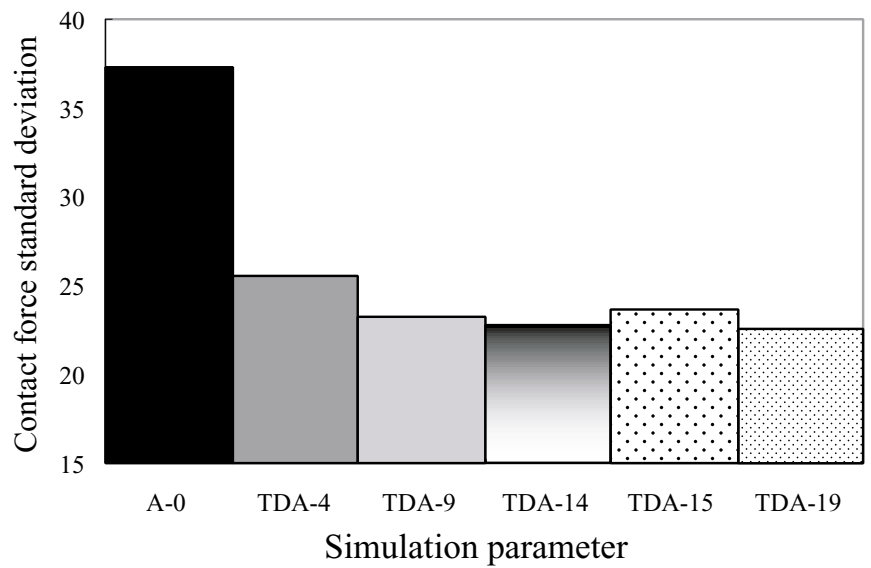

Fig. 12 Contact force standard deviation of the fifth pantograph (bilaterally effective damper)

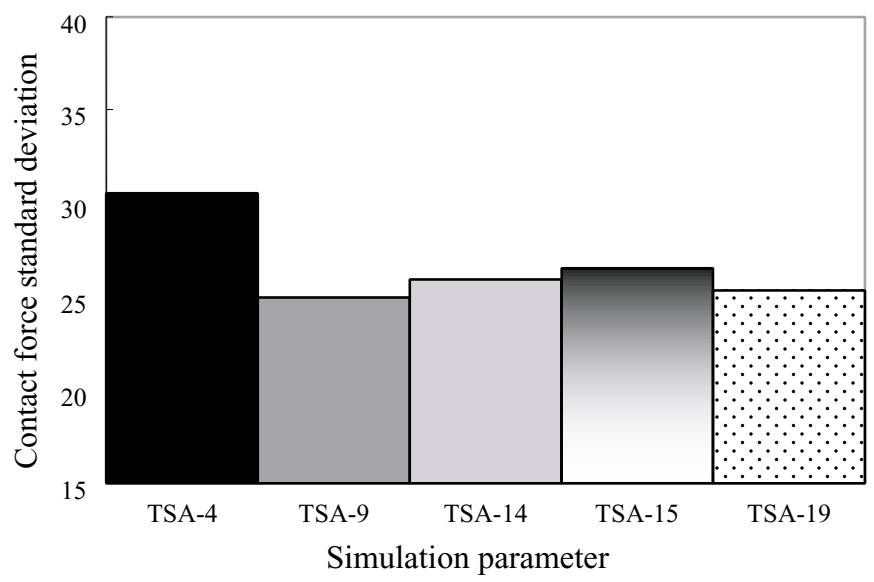

Fig. 13 Contact force standard deviation of the fifth pantograph (single-side effective damper)

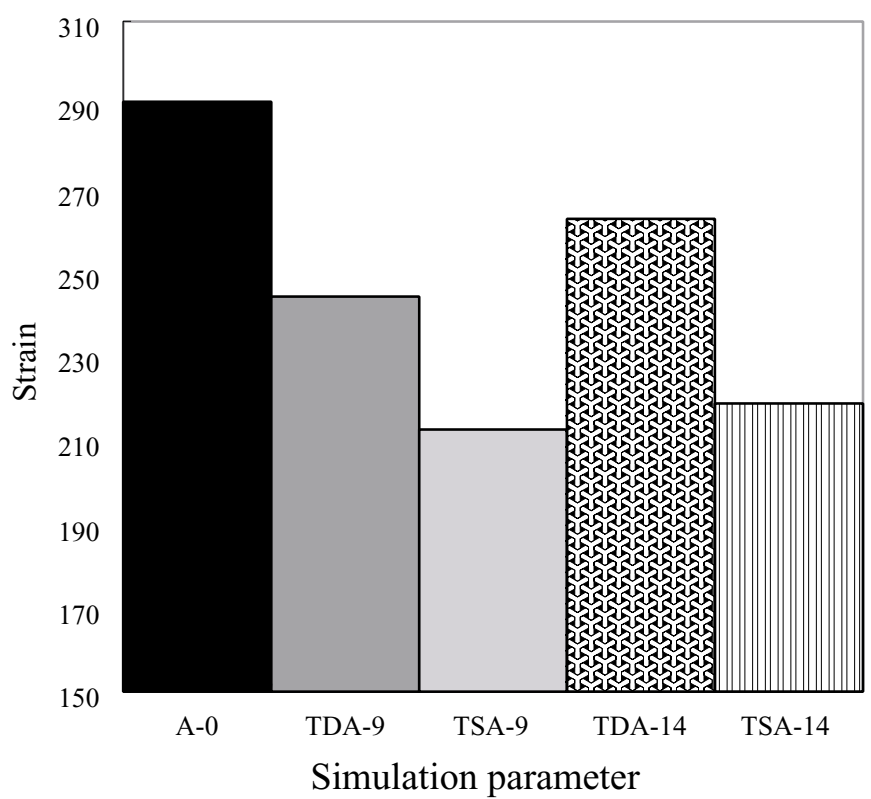

Fig. 14 Contact wire strain (difference between minimum and maximu) 
reduce the reflection wave and simulated it to confirm the effective use of a damper.

- The damper constant and installation point have to satisfy equations (11) and (14).

- A bilaterally effective damper should be used for messenger wires.

- A single-side effective damper should be used for contact wires.

Future subjects are to substantiate these results, we would examine these at real instruments.

\section{References}

1) 1) Manabe, K.: "A Study on Periodic Dynamic Response of a Catenary-Pantograph System (in
Japanese)," RTRI Report, Vol. 7, No. 10, 1993. 10.

2) Wu, T. X. and Brennan, M.J.: "Analytical study of patograph-catenary system dynamics," submitted to J. Vehicle System Dynamics, 1997.

3) Aboshi, M. and Nakai, I.: "Reduction of Catenary Vibration in High-speed Running (in Japanese)," RTRI Report, Vol. 9, No. 9, 1995. 9.

4) Manabe, K. and Arimoto, H.: "The Analysis of the Overhead Contact System by Digital Computer Simulation," Quarterly Report of RTRI, Vol. 12, No. 1, 1971.

5) Hayasaka, T and Yoshizawa, T.: "Study on Reduction of Reflective Wave of Contact Wire in Overlap Section (in Japanese)," The proceedings on Annual Meeting of IEEJ Industrial Application Society, No. 116, 2002. 8 . 